\title{
OBTENÇÃO DE GELATINA DE PELES DE CARPA HÚNGARA (Cyprinus carpio) E SUA MODIFICAÇÃO
}

\author{
T. M. QUINTANA ${ }^{1}$, J. P. SANTOS ${ }^{1}$, M. B. BEHLING ${ }^{1}$, P. H. HOFFMANN ${ }^{1}$, V. M. \\ ESQUERDO $^{1}$ e L. A. de A. PINTO ${ }^{1}$ \\ ${ }^{1}$ Universidade Federal do Rio Grande, Escola de Química e Alimentos \\ E-mail para contato: nessafurg@gmail.com
}

\begin{abstract}
RESUMO - O aproveitamento de resíduos gerados durante o processamento do pescado é um grande desafio para a cadeia produtiva da piscicultura. A utilização de subprodutos de pescado para produção de gelatinas vem sendo largamente estudada, devido aos resultados mostrarem que esta é uma fonte potencial para diferentes produtos. O objetivo deste trabalho foi a utilização de peles de carpa húngara (Cyprinus carpio) para obtenção de gelatina e posterior modificação. As gelatinas foram modificadas com a adição de agentes químicos. Foram utilizados os sais de $\mathrm{MgSO}_{4}, \mathrm{CuSO}_{4}$ e os componentes orgânicos ácido gálico e glicerol. As gelatinas com e sem modificação foram analisadas quanto à cor, viscosidade, força do gel e ponto de fusão. A gelatina de peles de carpa húngara foi extraída e modificada. A gelatina sem modificação apresentou ângulo Hue de $74,8^{\circ}$, e as gelatinas modificadas apresentaram coloração semelhante, com exceção da gelatina modificada com o sal $\mathrm{CuSO}_{4}$ que apresentou coloração verde-azulada (Hue de $199^{\circ}$ ). A gelatina sem modificação apresentou viscosidade de $5,5 \mathrm{cP}$, ponto de fusão de $27,2^{\circ} \mathrm{C}$ e força do gel de $197,4 \mathrm{~g}$. Com a modificação, a adição de glicerol foi a que apresentou melhores resultados, com um aumento da viscosidade para 6,4 $\mathrm{cP}$ e da força do gel para 199,9 g, proporcionando uma melhoria na qualidade da gelatina de pescado.
\end{abstract}

\section{INTRODUÇÃO}

O Brasil é considerado um dos países com maior potencial para a expansão da aquicultura, principalmente pela extensão dos recursos hídricos (Carneiro et al., 2004). As carpas produzidas através do sistema de policultivo integrado com outros animais lideram as estatísticas de produção de peixes cultivados no Brasil, e confirmam a importância da piscicultura orgânica. Resíduos gerados durante o processamento da carpa podem totalizar $60 \%$ da matéria-prima, e são principalmente constituídos por peles, cabeças e espinhaços (Kolodziejska et al., 2008).

A utilização e eliminação dos resíduos de pescado é difícil devido à sua instabilidade biológica, natureza potencial para crescimento de patógenos, elevada atividade de água e elevados níveis de atividade enzimática, que favorecem sua deterioração e oxidação. (Jayasinghe e Hawboldt, 2012). Entretanto, o aproveitamento destes resíduos para a elaboração de produtos de maior valor agregado aumentaria o faturamento das empresas e reduziria problemas ambientais (Aewsiri et al., 2008). Várias pesquisas vem sendo desenvolvidas na literatura para utilização dos resíduos de pescado, tais como extração de 


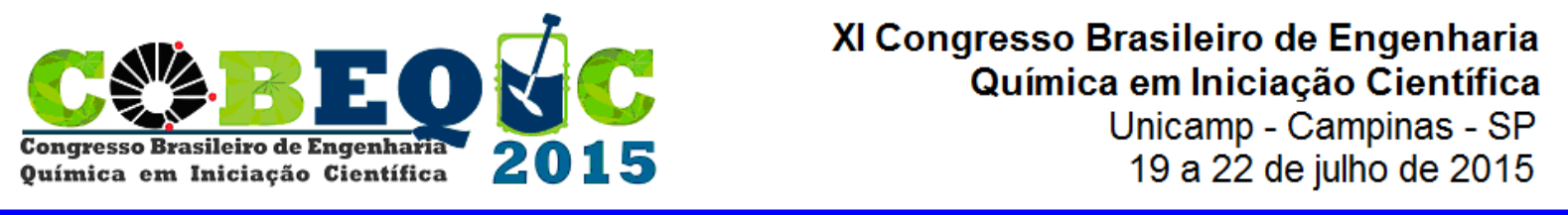

gelatina (Silva et al., 2011), obtenção de colágeno (Nalinanon et al., 2011) e produção de gelatina modificada (Yang et al., 2011).

A gelatina é uma mistura de peptídeos e proteínas biopoliméricas, obtida pela hidrólise parcial do colágeno animal, contido em ossos e peles (Shakila et al., 2012). A conversão do colágeno em gelatina pode ser obtida através do aquecimento deste, em meio ácido ou alcalino. As propriedades funcionais das gelatinas são dependentes das suas propriedades físico-químicas e estruturais, que são determinantes para definir sua aplicabilidade. A qualidade de uma gelatina é determinada por parâmetros como força do gel, viscosidade e ponto de fusão (Silva et al., 2011).

Sendo assim, este trabalho teve como objetivo o aproveitamento das peles de carpa húngara (Cyprinus carpio) para obtenção de gelatina e posterior modificação. As gelatinas com e sem modificação foram analisadas quanto à cor, viscosidade, força do gel e ponto de fusão.

\section{MATERIAL E MÉTODOS}

\subsection{Matéria prima}

O colágeno utilizado para obtenção de gelatina foi extraído de peles de carpa húngara (Cyprinus carpio), os quais foram fornecidos por piscicultores das cidades de Ajuricaba - RS e Canguçu - RS.

\subsection{Extração e modificação da gelatina}

As amostras de peles de carpa (400 g) foram cortadas $(1 \mathrm{~cm} \mathrm{x} 1 \mathrm{~cm})$ e após submetidas ao intumescimento com o primeiro tratamento alcalino, onde o seu $\mathrm{pH}$ foi ajustado para 11, com solução de $\mathrm{NaOH} 3 \mathrm{M}$, por 15 min sob agitação constante. Após drenagem, foi realizado o segundo tratamento alcalino, nas mesmas condições por $60 \mathrm{~min}$. As peles foram lavadas até neutralizar o pH e submetidas ao tratamento ácido em solução de $\mathrm{HCl} 3 \mathrm{M}$ por 15 min, ajustando-se o $\mathrm{pH}$ para 2. O processo de extração da gelatina pré-tratada foi realizado com adição de água destilada $(1: 1 \mathrm{~m} / \mathrm{v})$ à $52^{\circ} \mathrm{C}$, por de $2 \mathrm{~h}$ e $\mathrm{pH} 4$ (ajustado com solução de $\mathrm{HCl} 3$ M). A solução de gelatina extraída foi filtrada em funil de Büchner com papel filtro Whatman $n^{\circ} 4$.

Para remoção da sujidade e odores indesejados, a solução de gelatina foi submetida à clarificação com carvão ativado ( $1 \mathrm{~g}$ de clarificante $/ \mathrm{kg}$ de solução), por $120 \mathrm{~min}$ à $35^{\circ} \mathrm{C}$ sob agitação constante. A solução foi filtrada à vácuo em funil de Büchner com papel filtro Whatman $\mathrm{n}^{\circ} 4$ utilizando uma pré-capa de auxiliar de filtração (terra diatomácea), para remoção do agente clarificante. Após foi adicionado sorbato de potássio $(1 \% \mathrm{~m} / \mathrm{m}$, em relação à gelatina seca) como conservante na solução de gelatina, e esta foi posteriormente armazenada sob refrigeração à $5^{\circ} \mathrm{C}$.

Com o intuito de melhorar as características da gelatina obtida, as soluções foram modificadas com adição de agentes químicos. Foram utilizados os sais de $\mathrm{MgSO}_{4}, \mathrm{CuSO}_{4}$ ( $0,8 \mathrm{~mol} / \mathrm{L})$ e os componentes orgânicos ácido gálico $(20 \mathrm{mg} / \mathrm{g}$ de gelatina seca) e glicerol 


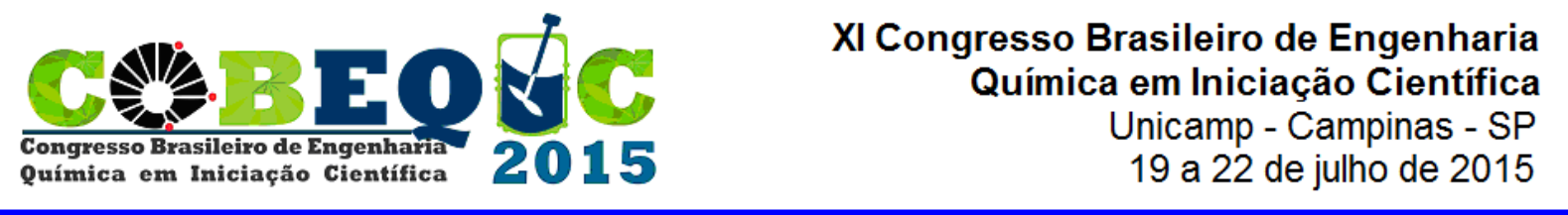

$(10 \%, \mathrm{~m} / \mathrm{m})$. Após a adição dos agentes à gelatina, as soluções foram mantidas à $45^{\circ} \mathrm{C}$ por 30 min em banho termostatizado para posterior caracterização.

\subsection{Caracterização das gelatinas}

As gelatinas foram caracterizadas quanto à cor, força do gel, viscosidade e ponto de fusão. A cor foi medida através do ângulo de cor Hue, utilizando um colorímetro (CR 300 , Minolta, EUA), e a luminosidade $L^{*}$ que corresponde do escuro ao claro (0, preto; 100 branco). Os valores de croma $a^{*}$ correspondem à escala do verde ao vermelho, e os valores de croma $b^{*}$ correspondem à escala do azul ao amarelo.

A força do gel foi determinada segundo Arnesen e Gildberg (2006). A gelatina (6,67\% $\mathrm{m} / \mathrm{v}$ ), foi aquecida a $45^{\circ} \mathrm{C}$ por 30 min e posteriormente refrigerada à $4^{\circ} \mathrm{C}$ por $17 \pm 1 \mathrm{~h}$. A força do gel foi medida em analisador de textura (TA.XTplus, Stable Micro Systems, Inglaterra), usando sonda de teflon com $12,5 \mathrm{~mm}$ de diâmetro pressionando $4 \mathrm{~mm}$ na gelatina à velocidade de $1 \mathrm{~mm} / \mathrm{s}$.

Para a análise da viscosidade, a amostra $(6,67 \% \mathrm{~m} / \mathrm{v})$ foi fundida em banho à $45^{\circ} \mathrm{C}$ e transferida para um viscosímetro capilar (Ostwald-Fensk nº 100 , Alemanha). O viscosímetro foi colocado em banho à $60^{\circ} \mathrm{C}$ por 10 min até a estabilização da temperatura. Assim a viscosidade $(\mu)$ pode ser calculada pela Equação 1:

$$
\mu=\mathrm{t} . \mathrm{K} . \rho
$$

onde $\mu$ é a viscosidade da solução de gelatina $(\mathrm{cP})$ à $60^{\circ} \mathrm{C}$, t é o tempo de escoamento (s), $\mathrm{K}$ é a constante do viscosímetro (cSt/s) e $\rho$ é a massa específica da solução $(\mathrm{g} / \mathrm{mL})$.

Para determinação do ponto de fusão foram adicionadas, sobre o gel de gelatina $(6,6 \%$ $\mathrm{m} / \mathrm{v}$ ), cinco gotas de uma mistura de $75 \%$ de clorofórmio e $25 \%$ do corante azul de metileno. $\mathrm{O}$ gel foi colocado em banho termostatizado a $15^{\circ} \mathrm{C}$, tendo sua temperatura elevada em $0,1^{\circ} \mathrm{C}$ a cada 2 min. O ponto de fusão é o valor da média entre a temperatura no momento da penetração das gotas, e a temperatura em que a solução estiver completamente corada (Choi e Regenstein 2000).

\section{RESULTADOS E DISCUSSÃO}

A Figura 1 apresenta as amostras de gelatina extraída de pele de carpa húngara sem modificação e das gelatinas modificadas com $\mathrm{CuSO}_{4}$, glicerol, ácido gálico e $\mathrm{MgSO}_{4}$.

Figura 1 - Amostras de gelatinas obtidas de peles de carpa húngara - (a) sem modificação, e modificadas com (b) $\mathrm{CuSO}_{4}$, (c) glicerol, (d) ácido gálico, (e) $\mathrm{MgSO}_{4}$

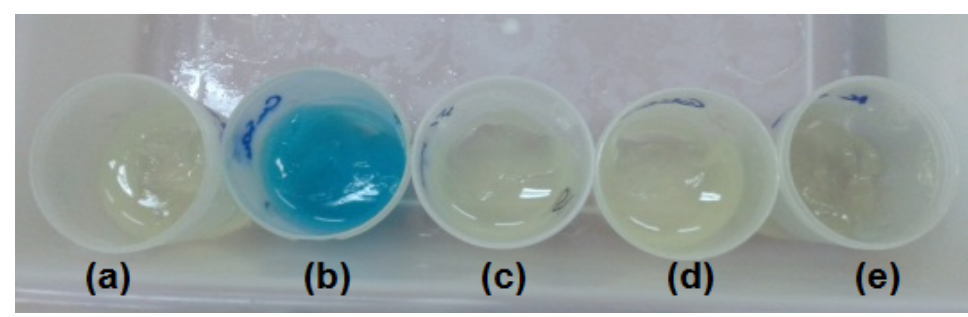


A Tabela 1 apresenta os valores do ângulo Hue das gelatinas das peles de carpa húngara antes e após a modificação pela ação dos agentes de reticulação.

Tabela 1 - Valores dos ângulos Hue das gelatinas obtidas de peles de carpa húngara antes e após modificação

\begin{tabular}{cccccc} 
Amostras & $\begin{array}{c}\text { Gelatina sem } \\
\text { modificação }\end{array}$ & $\mathbf{C u S O}_{4}$ & glicerol & Ácido gálico & MgSO $_{4}$ \\
\hline Ângulo Hue $\left(^{\circ}\right)$ & $74,8 \pm 0,6$ & $199,0 \pm 1,3$ & $80,6 \pm 0,9$ & $80,2 \pm 0,9$ & $79,4 \pm 1,0$ \\
\hline
\end{tabular}

*Médias \pm desvio padrão $(\mathrm{n}=3)$.

Através da Tabela 1 e da Figura 1 pode-se observar que apenas a gelatina modificada com o sal $\mathrm{CuSO}_{4}$ não apresentou coloração característica de gelatina de pescado (Hue próximo a $90^{\circ}$ ), a mesma tendeu ao verde-azulado (Hue entre $180^{\circ}$ e $270^{\circ}$ ). Apesar de não alterar as propriedades funcionais das gelatinas, a cor é um importante atributo que deve ser considerado, dependendo da aplicação a qual se destina o produto final (Ahmad e Benjakul, 2011).

A Tabela 2 apresenta o comportamento das propriedades viscosidade, ponto de fusão e força do gel para as gelatinas de peles de carpa húngara antes e após a modificação pela ação dos agentes de reticulação.

Tabela 2 - Valores de força de gel, ponto de fusão, turbidez e viscosidade das gelatinas obtidas de peles de carpa húngara antes e após modificação

\begin{tabular}{|c|c|c|c|}
\hline Amostras & $\begin{array}{c}\begin{array}{c}\text { Viscosidade* } \\
(\mathrm{cP})\end{array} \\
\end{array}$ & Ponto de Fusão* $\left({ }^{\circ} \mathrm{C}\right)$ & $\begin{array}{c}\text { Força do Gel* } \\
(\mathrm{g})\end{array}$ \\
\hline $\begin{array}{l}\text { Gelatina sem } \\
\text { modificação }\end{array}$ & $5,5 \pm 0,2$ & $27,2 \pm 0,4$ & $197,4 \pm 0,5$ \\
\hline $\mathrm{CuSO}_{4}$ & $5,8 \pm 0,3$ & $27,3 \pm 1,1$ & $175,9 \pm 0,9$ \\
\hline Glicerol & $6,4 \pm 0,4$ & $25,3 \pm 0,9$ & $199,9 \pm 0,7$ \\
\hline Ácido gálico & $4,9 \pm 0,7$ & $26,5 \pm 0,8$ & $192,6 \pm 0,6$ \\
\hline $\mathrm{MgSO}_{4}$ & $6,3 \pm 0,3$ & $25,4 \pm 0,7$ & $168,1 \pm 1,0$ \\
\hline
\end{tabular}

*Médias \pm desvio padrão $(\mathrm{n}=3)$.

As medidas de viscosidade das gelatinas são influenciadas pelas concentrações e tipos de gelatina, temperatura e condições do método de processamento utilizado (Gudmundsson, 2002). Gelatinas com baixa viscosidade resultam em géis frágeis, enquanto gelatinas de alta viscosidade produzem géis consistentes e extensíveis (Wainewright, 1977). No presente trabalho a viscosidade da gelatina sem modificação foi de 5,5 cP. Alfaro (2008) encontrou 6,1 cP para a viscosidade de gelatina extraída das peles de tilápia. Ao modificar a gelatina de 


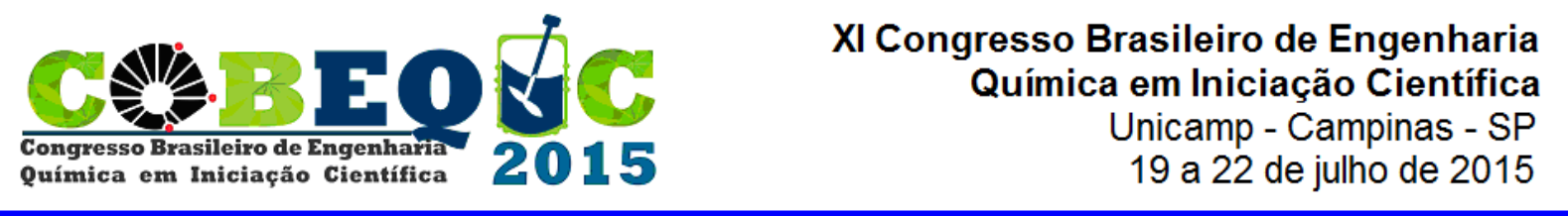

pescado, foi possível melhorar esta propriedade, elevando seu valor para 6,3 cP e 6,4 cP com os agentes reticulantes $\mathrm{MgSO}_{4}$ e glicerol, respectivamente.

Quanto à temperatura de fusão (Tabela 2), a gelatina de carpa húngara sem modificação apresentou um valor de semelhante aos resultados encontrados para gelatina suína por Bueno (2008) de $27,5^{\circ} \mathrm{C}$. No entanto, para a gelatina modificada com glicerol, o ponto de fusão foi menor, sendo o resultado próximo aos de Cheow et al. (2007) na análise das propriedades viscoelásticas das soluções de gelatina obtidas de peles de corvina, onde a temperatura de fusão encontrada foi de $24,9^{\circ} \mathrm{C}$. A temperatura de fusão de gelatina de pescado pode apresentar variações em função de muitos fatores, tais como, a fonte de colágeno, método de preservação da matéria-prima, condições de extração da gelatina, composição em aminoácidos, entre outros.

A força de gel de uma gelatina comercial varia de 100-300 g. Geralmente, quanto maior os valores de força de gel, melhor a qualidade da gelatina (Wang et al., 2008). Observando os valores da força de gel apresentados na Tabela 2, nota-se a gelatina modificada com glicerol apresentou um aumento quando comparada a gelatina de pele de carpa húngara sem modificação.

\section{CONCLUSÃO}

A gelatina de peles de carpa húngara (Cyprinus carpio) foi extraída e caracterizada. A partir dos resultados obtidos pode-se observar que com exceção da gelatina modificada com o sal $\mathrm{CuSO}_{4}$ que apresentou coloração verde-azulada (Hue 199 ${ }^{\circ}$ ), as gelatinas apresentaram coloração característica de gelatina de pescado (Hue próximo a $90^{\circ}$ ). A modificação da gelatina de carpa com glicerol resultou em um aumento na viscosidade $(6,4 \mathrm{cP})$ e na força do gel (199 g) quando comparada a gelatina sem modificação (5,5 cP e 197 g), proporcionando uma melhoria na qualidade material.

\section{REFERÊNCIAS}

AEWSIRI, T.; BENJAKUL, S.; VISESSANGUAN, W.; TANAKA, M. Chemical compositions and functional properties of gelatin from pre-cooked tuna fin. Int. J. Food Sci. Technol., v. 43, p. 685-693, 2008.

AHMAD, M.; BENJAKUL, S.; OVISSIPOUR, M.; PRODPRAN, T. Indigenous proteases in the skin of unicorn leatherjacket (Alutherus monoceros) and their influence on characteristic and functional properties of gelatin. Food Chem. v. 127, 508-515, 2011.

ALFARO, A. T. Otimização das condições de extração e caracterização da gelatina de pele de tilápia (Oreochromis urolepis hornorum). Tese de Doutorado em Ciência e Tecnologia Agroindustrial - Universidade Federal de Pelotas (UFPel), Pelotas, 2008.

ARNESEN, J. A.; GILDBERG, A. Extraction of muscle proteins and gelatin from cod head. Process Biochem., v. 41, p. 697-700, 2006.

BUENO, C. M. M. Extração e caracterização de gelatina de pele de tilápia e aplicação como agente encapsulante de óleo de salmão em micropartículas obtidas por coacervação complexa. 133 f. Dissertação (Mestre em Alimentos e Nutrição) - Faculdade de Engenharia de Alimentos, Universidade Estadual de Campinas, Campinas, SP, 2008. 
CARNEIRO, R. L.; SILVA, J. A. M.; ALBINATI, R. V. B.; SOCORRO, E. P.; NEVES, A. P. Uso do microcrustáceo branchoneta (Dendrocephalus brasiliensis) na ração para tucunaré. Revista Brasileira de Saúde e Produção Animal, v. 5, n.1, p. 8-24, 2004.

CHEOW, C. S.; NORZIAH, M. S.; KYAW, Z. Y.; HOWELL, N. K. Preparation and characterisation of gelatins from the skins of sin croaker (Johnius dussumieri) and shortfin scad (Decapterus macrosoma). Food Chem. v.101, 386-391, 2007.

CHOI, S. S.; REGENSTEIN, J. M. Physicochemical and sensory characteristics of fish gelatin. J. Food Sci, v. 65, p. 194-199, 2000.

GUDMUNDSSON, M.; Rheological properties of fish gelatin. J. Food Sci., v.67, p. 21722176, 2002.

JAYASINGHE, P.; HAWBOLDt, K. A review of bio-oils from waste biomass: focus on fish processing waste. Renewable Sustainable Energy Rev., v. 16, p. 798-821, 2012.

KOLODZIEJSKA, I; SKIERKA, E; SADOWSKA, M; KOLODZIEJSKI, W; NIECIKOWSKA, C. Effect of extracting time and temperature on yield of gelatin from different fish offal. Food Chem., v. 107, p. 700-706, 2008.

NALINANON, S.; BENJAKUl, S.; KISHIMURA, H.; OSAKO, K. Type I collagen from the skin of ornate threadfin bream (Nemipterus exodon): Characteristics and effect of pepsin hydrolysis. Food Chem., v. 125, n. 2, p. 500-507, 2011

SHAKILA, R.J.; JEEVITHAN, E.; VARATHARAJAKUMAR, A.; JEYASEKARAN, G.; SUKUMAR, D. Functional characterization of gelatin extracted from bones of red snapper and grouper in comparison with mammalian gelatin. Food Sci. Technol., v.48, 30-36, 2012.

SILVA, R. S. G; BANDEIRA, S. F; PETRY, F. C; PINTO, L. A. A. Extração de gelatina a partir das peles de cabeça de carpa comum. Ciência Rural, v.41, n. 5, p. 904-909, 2011.

WAINEWRIGHT, F. W. Physical test for gelatin and gelatin products. In A. G. Ward; A. Courts (Eds.), The science and technology of gelatins (pp. 507-534). Academic Press Inc. New York, 1977.

WANG, L.; YANG, B.; DU, X.; YANG, Y.; LIU, J. Optimization of conditions for extraction of acid-soluble collagen from grass carp (Ctenopharyngodon idella) by response surface methodology. Food Sc. Emerg. Technol.. v.9, n. 4, p. 604-607, 2008

YANG, Z.; WU X.; LI, T.; LI, M.; ZHONG, Y.; LIU, Y.; DENG, Z.; DI, B.; HUANG, C.; LIANG, H.; WANG, M. Epidemiological survey and analysis on an outbreak of gastroenteritis due to water contamination. Biomed. Environ. Sci., v. 24, p. 275-83. 2011. 